This item was submitted to Loughborough's Research Repository by the author.

Items in Figshare are protected by copyright, with all rights reserved, unless otherwise indicated.

\title{
In situ spectroelectrochemistry and colour measurement of a complementary electrochromic device based on surface-confined Prussian blue and aqueous solution-phase methyl viologen
}

\section{PLEASE CITE THE PUBLISHED VERSION}

http://dx.doi.org/10.1016/j.solmat.2011.11.052

\section{PUBLISHER}

(C) Elsevier B.V.

\section{VERSION}

AM (Accepted Manuscript)

\section{LICENCE}

CC BY-NC-ND 4.0

\section{REPOSITORY RECORD}

Mortimer, Roger J., and Thomas S. Varley. 2019. "In Situ Spectroelectrochemistry and Colour Measurement of a Complementary Electrochromic Device Based on Surface-confined Prussian Blue and Aqueous Solutionphase Methyl Viologen". figshare. https://hdl.handle.net/2134/11418. 
This item was submitted to Loughborough's Institutional Repository (https://dspace.lboro.ac.uk/) by the author and is made available under the following Creative Commons Licence conditions.

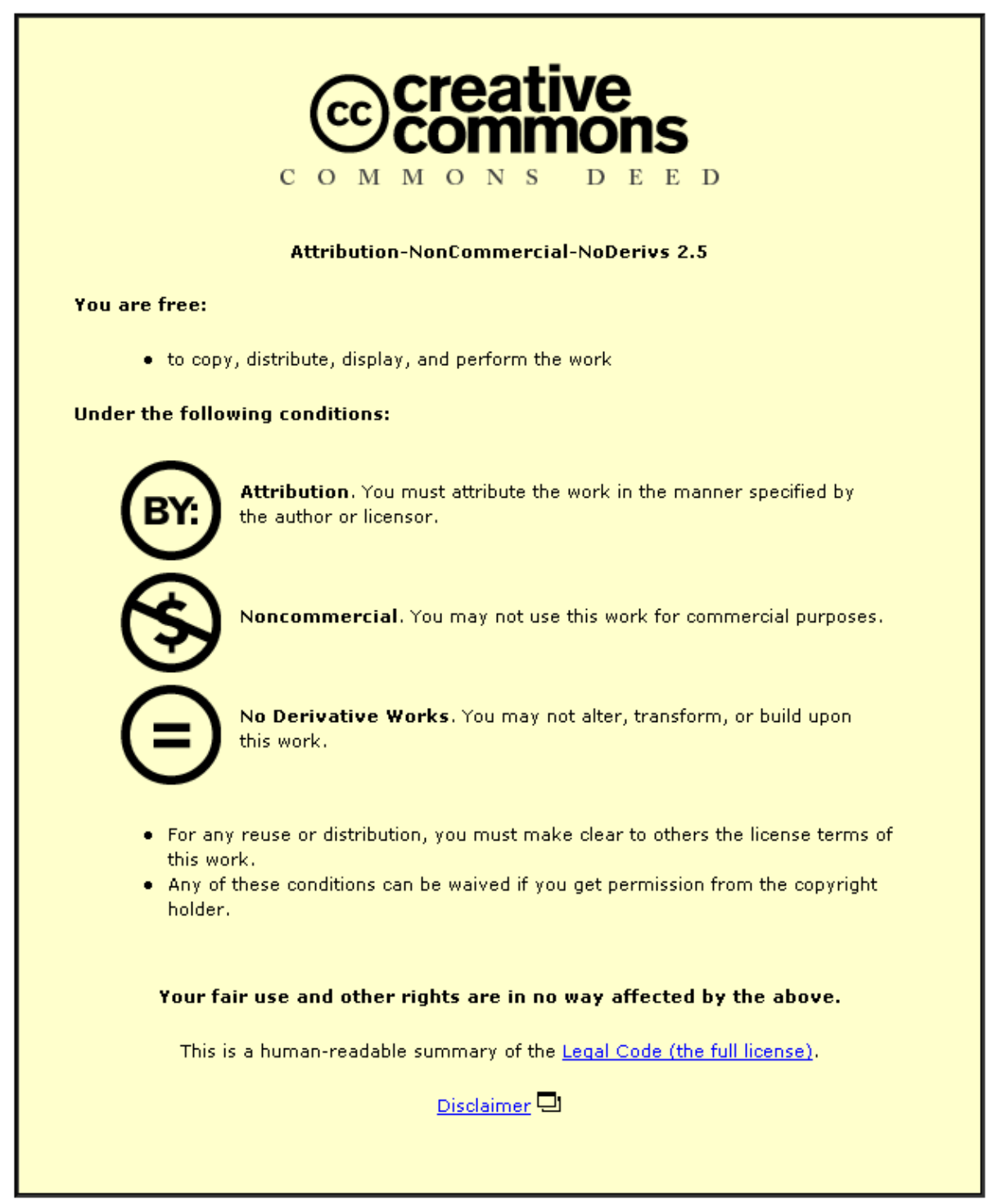

For the full text of this licence, please go to: http://creativecommons.org/licenses/by-nc-nd/2.5/ 


\title{
In situ spectroelectrochemistry and colour measurement of a complementary electrochromic device based on surface-confined Prussian blue and aqueous solution- phase methyl viologen
}

\author{
Roger J. Mortimer*, Thomas S. Varley \\ Department of Chemistry, Loughborough University, \\ Loughborough, Leicestershire, LE11 3TU, UK \\ *Corresponding author: Tel. +44 (0)1509 222583 Fax +44 (0)1509 223925 \\ E-mail address: R.J.Mortimer@lboro.ac.uk
}

\begin{abstract}
The fabrication, in situ spectroelectrochemistry and colour measurement of hybrid electrochromic devices (ECDs) based on a surface-confined metal hexacyanometallate - Prussian blue (PB, containing the iron(III) hexacyanoferrate(II) chromophore) - and aqueous solution-phase methyl viologen ( $N, N^{\prime}$-dimethyl-4,4'-bipyridylium) are described. In the ECDs, the initial ('off') bleached state is set with PB in its reduced form and the methyl viologen as the di-cation. Switching to the coloured state ('on'), forms the mixed-valence iron(III) hexacyanoferrate(II) chromophore on oxidation of iron(II) hexacyanoferrate(II), with simultaneous reduction of the methyl viologen dication to form a mixture of the radical cation monomer/dimer. Using the Commission Internationale de l'Eclairage (CIE) system of colorimetry, the colour stimulus of such ECDs and the changes that take place on reversibly switching between the colourless and coloured states have been calculated from in situ visible region spectra recorded under electrochemical control. The concentration of the solution-phase methyl viologen and its diffusion to the cathode controlled both the proportion of surface-confined (reduced) PB that is switched to the blue form and the overall ECD changes. For the ECDs' 'on' states, the CIELAB 1976 color space coordinates for a D55 illuminant were $L^{*}=60, a^{*}=3$ and $b^{*}=-46$, and $L^{*}=49, a^{*}=9$ and $b^{*}=-59$, respectively for 5 and $10 \mathrm{mM}$ methyl viologen solution concentrations. The low $a^{*}$ and high (negative) $b^{*}$
\end{abstract}


chromaticity coordinates quantified the overall ECD colour stimulus of the 'on' state as being deep blue, with a broad absorption across the visible spectral region. Combination of the methyl viologen system in the ECDs served to remove the green tint perceived in single film PB. CIELAB 1976 colour space coordinates showed that the ECDs were fully transparent and nearly colourless in the 'off' states, with $L^{*}=100, a^{*}=1$ and $b^{*}=1$. The changes in the transparency were $83.0 \%$ (5 mM methyl viologen) and 93.1\% (10 mM methyl viologen) between the 'off' (bleached) and 'on' (coloured) states of the ECDs.

\section{Keywords}

Electrochromic; Electrochromism; Prussian blue; Methyl viologen; CIE chromaticity coordinates; Colorimetry

\section{Introduction}

Electrochromic materials have the property of a change, evocation, or bleaching, of colour as effected either by an electron-transfer (redox) process or by a sufficient electrochemical potential $[1,2]$. Many chemical materials exhibit two or more redox states with distinct electronic (UV/visible) absorption spectra, which arise from either a moderate energy internal electronic excitation or an intervalence optical charge transfer. Applications of electrochromic materials include 'smart' windows [3] and anti-glare car mirrors [4, 5], based on modulation of transmitted and reflected visible radiation, respectively. Commercial successes include the electrochromic adjustable-darkening windows that reduce cabin glare in the new Boeing 787 Dreamliner aircraft and Gentex Corporation's NVS ${ }^{\circledR}$ car mirrors that automatically dim to eliminate headlamp glare. Proposed applications include (non-emissive) controllable light-transmissive or light-reflective display devices for optical information and storage, re-usable price labels, protective eyewear, controllable aircraft canopies, glare-reduction systems for offices, and chameleonic fabrics.

When developing electrochromic materials for possible applications, prototype electrochromic devices (ECDs) are generally fabricated using optically-transparent electrodes in a 'sandwich' configuration, the primary electrochromic electrode and charge-balancing secondary electrode being separated by a layer of liquid, gel, or solid electrolyte [1, 2]. The operating principle is as for a rechargeable thin-film battery; on application of an appropriate electrical potential, the charge/discharge process provides switching between colour states. ECDs are designed to operate in either absorptive/transmissive or reflective modes. For absorptive/transmissive ECDs, the secondary electrode redox reaction is chosen to be a system where there is imperceptible visible colour change or as an electrochromic material where the change in colour is complementary or 
reinforcing to that at the primary electrochromic electrode, thus providing enhancement of the coloured/bleached contrast. ECDs that operate in a reflective mode employ a polished metal (or a reflective coating), in place of or behind, the rear optically-transparent electrode.

We here describe the fabrication, in situ spectroelectrochemistry and colour measurement of hybrid ECDs based on a surface-confined metal hexacyanometallate - Prussian blue (PB, containing the iron(III) hexacyanoferrate(II) chromophore) - and aqueous solution-phase methyl viologen ( $N, N^{\prime}$-dimethyl-4,4'-bipyridylium). Fig. 1 shows the separate spectra of the coloured states of these electrochromic materials. The intense colour of the iron(III) hexacyanoferrate(II) chromophore in PB arises from intervalence charge-transfer (IVCT) between the mixed-valence iron(III/II) oxidation states [6]. Methyl viologen di-cations in solution are colourless, but absorb strongly in the UV region, reductive electron transfer forming the radical cation, the stability of which is attributable to the delocalisation of the radical electron throughout the $\pi$-framework of the bipyridyl moiety [7]. Viologen radical cations are intensely coloured, with high molar absorption coefficients, owing to optical charge transfer between the (formally) +1-valent and zero-valent nitrogens [7]. In aqueous electrolyte solution, the blue methyl viologen radical cation is in equilibrium with the red methyl viologen cation dimer [8], the resulting observable colour being an intense purple.

We have earlier investigated the in situ colorimetry of thin-film PB [9] and have established that although always described as Prussian blue, this material is tinted with green. We therefore anticipated that in the ECDs' 'on' state, combination of blue (with green tint) and purple would provide deeper coloration, towards black, with a broad spectral absorption in the visible region from the overlap of the spectra of the individual materials (Fig. 1).

Figure 1 here

In the fabrication of the ECDs described here, the PB is first reduced to the colourless iron(II) hexacyanoferrate(II) form. The colour-forming reactions at each electrode in the PB/methyl viologen ECDs are then shown in Scheme 1, the observed overall colour state being a combination of the two coloured forms.

Scheme 1 here

Earlier reports where the anodically-coloring PB has been paired with cathodically-coloring materials are exclusively restricted to ECDs where the cathodically-coloring material is likewise 
surface-confined. Thus PB has been paired with tungsten trioxide $\left(\mathrm{WO}_{3}\right)$ (colourless to blue on reduction) [10, 11, 12], poly[3,4-(ethylenedioxy)thiophene] (PEDOT) (light blue transmissive to deep blue on reduction) [13], poly[3,3-diethyl-3,4-dihydro-2H-thieno-[3,4-b][1,4]dioxepine] (PProDOT-Et 2 ) (light blue transmissive to deep blue-violet on reduction) [14] and poly(butyl viologen) (colourless to purple on reduction) [15].

In the present work we show that the extent of the overall colour change may be controlled by the choice of methyl viologen solution concentration and demonstrate how the colour changes may be quantified using CIE (Commission Internationale de l'Eclairage) principles. For application in the field of electrochromism, in 2000 Reynolds and co-workers introduced an in situ colour measurement ('colorimetry') method for the precise measurement and control of colour in electrochromic materials and ECDs [16]. This methodology, with use of a simple portable colorimeter, has since been extensively applied to colour measurement of numerous electrochromic conjugated polymer films and devices [17-39], thin films of PB [9], a viologen-based electrochromic plastic device [40], and the $n$-heptyl viologen system [41]. In the results presented here, chromaticity coordinates and luminance data were calculated from in situ visible region absorption spectra recorded in transmission mode under electrochemical control.

\section{Experimental}

\subsection{ECD Fabrication}

Tin-doped indium oxide (ITO)-coated optically transparent substrates (Corning 1737 aluminosilicate glass, 25 × 25 x $1.1 \mathrm{~mm}, R_{\mathrm{S}} 4-8 \Omega \square^{-1}$ (CB-50IN-0111)) were from Delta Technologies. Scanning electron microscopy (SEM) here confirmed the uniformity of the $100 \mathrm{~nm}$ thick sputtered ITO films. Fig. 2 shows photographs that summarise the ECD construction at four key stages, the design allowing spectral measurements to be made in transmission mode.

Figure 2 here

The ITO/glass substrates were patterned by wet chemical etching at $50^{\circ} \mathrm{C}$ for $90 \mathrm{~s}$ in an aqueous solution containing $6 \mathrm{M} \mathrm{HCl}$ and $0.2 \mathrm{M} \mathrm{FeCl}_{3} \cdot 6 \mathrm{H}_{2} \mathrm{O}$. The exposed area was defined by masking with Scotch ${ }^{\mathrm{TM}}$ Magic Tape (3M), ITO removal at the edges being confirmed by SEM and four-point probe conductance measurements. Although a rectangular shape was chosen here, in principle, using an appropriate stencil, any desired shape could be created onto the substrates' surface. PB thin films were deposited potentiostatically at $+0.50 \mathrm{~V}$ vs. $\mathrm{Ag} / \mathrm{AgCl}$ (3 $\mathrm{M} \mathrm{NaCl}$ ) for $300 \mathrm{~s}$ from fresh de-oxygenated aqueous solutions containing $5 \mathrm{mM} \mathrm{FeCl}_{3} \cdot 6 \mathrm{H}_{2} \mathrm{O}, 5 \mathrm{mM} \mathrm{K} 3 \mathrm{Fe}(\mathrm{CN})_{6}$, 
$0.01 \mathrm{M} \mathrm{HCl}$ and $0.2 \mathrm{M} \mathrm{KCl}$ [9]. Following deposition, PB thin films were subjected to 20 conditioning cycles, +0.50 to $-0.20 \mathrm{~V}$ vs. $\mathrm{Ag} / \mathrm{AgCl}(3 \mathrm{M} \mathrm{NaCl})$ at $50 \mathrm{mV} \mathrm{s}^{-1}$ in $0.2 \mathrm{M}$ aqueous $\mathrm{KCl}$. Electrochemical deposition provided smooth PB films, uniform to the eye, with an average film thickness of $320 \mathrm{~nm}$, as calculated from the $6.3 \mathrm{mC} \mathrm{cm}^{-2}$ charge passed on electrochemically switching colour states. For the $\sim 4 \mathrm{~cm}^{2}$ active ECD area, this corresponds to $\sim 2.6 \times 10^{-7}$ moles of surface-confined PB. Polyamide - Nylon 6 film (0.25 mm thick, from Goodfellows), was used as a spacer and secured to three sides of the PB-coated ITO/glass substrate using epoxy resin and positioned where ITO had been etched away. At the point where the ITO film extends to the edge of the slide, adhesive copper tape, as current collector, was then attached to the top edge of both slides, and coated with a thin layer of epoxy resin to prevent any copper coming into contact with the electrolyte solution. Epoxy resin was also used to secure the second slide onto the first, creating a small volume between the slides. Rinsing with $10 \mathrm{mM}$ ascorbic acid reduced the iron(III) hexacyanoferrate(II) chromophore in PB to the colourless/transparent iron(II) hexacyanoferrate(II) oxidation state. Finally, a 5 or $10 \mathrm{mM}$ methyl viologen dichloride in $0.5 \mathrm{M}$ aqueous $\mathrm{KCl}$ layer was injected with a micro-bore needle, through the top, unsealed side, or by capillary action on gently squeezing together the device and placing the unsealed edge into the solution and releasing. The upper opening was then sealed with epoxy resin.

\subsection{Electrochemical, spectroelectrochemical and colour measurement}

An ECO Chemie Autolab PGSTAT 20 potentiostat was used for electrode potential control. For the ECD experiments, the potentiostat working electrode lead was connected to the PB-coated ITO/glass electrode, with the counter and reference electrodes' leads shorted together and connected to the second ITO/glass electrode. In situ visible region spectra were recorded in transmission mode using a Hewlett Packard 8452A diode array spectrophotometer. CIE 1931 xy chromaticity coordinates and luminance data were calculated from the spectral absorbancewavelength data as described earlier [42]. For the simulation of mid-morning to mid-afternoon natural light, the relative spectral power distribution of a D55 constant temperature (5500 K black body radiation) standard illuminant was used in the calculations. Chromaticity coordinates were also transformed to CIELAB $L^{*} a * b *$ coordinates, a uniform colour space (CIELAB) defined by the CIE in 1976 [43].

\section{Results and discussion}

\subsection{Spectroelectrochemistry}


Separate PB/methyl viologen ECDs were investigated, with both 5 and $10 \mathrm{mM}$ methyl viologen dichloride/ $0.5 \mathrm{M} \mathrm{KCl}$ as the layer of liquid aqueous electrolyte. In order to determine the appropriate switching potentials of each ECD, potentials were applied, starting at the open circuit potential, $0.00 \mathrm{~V}$, and extending in both the positive and negative directions. The optimum switching potentials of the ECDs were established as $-1.00 \mathrm{~V}$ for the 'off' (colourless) state and $+1.50 \mathrm{~V}$ for the 'on' (coloured) state, representing a compromise between enhancing the switching kinetics and avoidance of over oxidation/reduction of the electrochromic materials and/or decomposition of the solvent. For each ECD, measurement of spectral data was repeated six times and found to be coincident. When the measurements were repeated after seven days, using no specific storage conditions and exposed to both light and air, the ECDs exhibited no degradation in appearance and performance. Continuous switching over several hours, holding each potential for $30 \mathrm{~s}$, led to no change in performance of the ECDs. Fig. 3 shows spectral changes on reversibly switching PB/methyl viologen ECDs at the two concentrations between the 'off' state (colourless) and the 'on' state, which appeared deep blue to the eye.

In our recent work [44] with hybrid ECDs based on the surface-confined metal hexacyanometallate, Ruthenium purple (containing the iron(III) hexacyanoruthenate(II) chromophore) and solution-based methyl viologen, the anode and cathode reactions simultaneously exhibited reversible colourless to intense purple changes, the overall ECD coloration being colour reinforcing. By contrast, the IVCT band (Fig. 1) in PB appears at a higher wavelength spectral region $\left(\lambda_{\max }=710 \mathrm{~nm}\right)$ than that in Ruthenium purple $\left(\lambda_{\max }=550 \mathrm{~nm}\right)$, the combination of the spectral bands (with $\lambda_{\max }=678 \mathrm{~nm}$ ) of the two colour states in a PB/methyl viologen ECD providing broad absorption (400 - $780 \mathrm{~nm}$ ) (Fig. 3 (a) to (d)) in the visible region, appearing deep blue by eye. In addition to absorption in the visible region, the spectral peaks below $400 \mathrm{~nm}$ (Fig. 3 (a) to (d)) are also due to the methyl viologen radical cation monomer/dimer, but do not contribute to the perceived colour.

Figure 3 here

Interestingly, the total absorbance change for the $5 \mathrm{mM}$ methyl viologen ECD (Fig. 3 (a), (b), (e)), was similar to that which would be obtained $(A=0.77)$ at a single electrode with surfaceconfined PB prepared under the same conditions [9]. That the PB contributes to the visible region absorption is proved by the higher ratio of absorption in this region compared to the spectral peaks below $400 \mathrm{~nm}$, in comparison to the spectral data (Fig. 1) of the methyl viologen radical cation system [42]. Although the amount of solution-phase methyl viologen ( $\sim 5 \times 10^{-7}$ moles, calculated 
from the product of the ECD internal volume (spacer thickness $(0.025 \mathrm{~cm}) \mathrm{x}$ area $\left.\left(4 \mathrm{~cm}^{2}\right)=0.1 \mathrm{~cm}^{3}\right)$ and the solution concentration $\left.\left(5 \times 10^{-6} \mathrm{~mol} \mathrm{~cm}^{-3}\right)\right)$, exceeds the amount of surface-confined $\mathrm{PB}$ ( $\sim 2.6 \times 10^{-7}$ moles), the ECD does not act as a thin-layer cell, where all solution redox species would be converted. When the ECD is switched 'on', not all the methyl viologen in the bulk solution is electrolysed. The concentration of methyl viologen and its diffusion to the cathode therefore control the proportion of surface-confined PB that is switched to the blue form. With use of higher methyl viologen concentrations, a greater depth of colour is accessible, for example, a 10 $\mathrm{mM}$ methyl viologen ECD provides a higher total absorbance change of just under twice (Fig. 3 (c), (d), (f)) that for a $5 \mathrm{mM}$ methyl viologen ECD. Transparency, expressed as changes in the transmittance were 83.0\% (5 mM methyl viologen) and 93.1\% (10 mM methyl viologen) between the 'off' (bleached) and 'on' (coloured) states of the ECDs. ECD contrast ratios, expressed as the ratio of the percentage transmitted light in the 'off' (bleached) to the percentage transmitted light in the 'on' (coloured) states were 6 (5 mM methyl viologen) and 15 (10 mM methyl viologen). Power consumption, expressed as the coloration efficiency (at the $\lambda_{\max }$ ) was 170 and $86 \mathrm{~cm}^{2} \mathrm{C}^{-1}$ for $5 \mathrm{mM}$ and $10 \mathrm{mM}$ methyl viologen, respectively. Compared to measurements for single surface-confined PB electrodes, where switching times were $<1 \mathrm{~s}$, ECD switching times are longer owing to the diffusional limitations of the solution-based methyl viologen system. Switching times, as estimated for $95 \%$ of the total absorbance change, were $\sim 10 \mathrm{~s}$, for colouration and bleaching for both the 5 and $10 \mathrm{mM}$ methyl viologen ECDs.

\subsection{CIE colour theory}

Colour is a subjective phenomenon $[45,46]$, however, much effort has been given to the development of colorimetry (colour measurement) [47], which allows a quantitative description of colour and relative transmissivity as sensed by the human eye. Colorimetry provides a more precise way to define colour than qualitatively interpreting spectral absorption bands. In colorimetry, the human eye's sensitivity to light across the visible region is measured and a numerical description of the colour stimulus is given. The first attribute for the description of colour identifies its location in the spectral sequence, i.e., what wavelength is associated with the colour. This is known as the hue, dominant wavelength, or chromatic colour, and is the wavelength where maximum contrast occurs. The second attribute, relating to the level of white and/or black, is known as saturation, chroma, tone, intensity, or purity. The third attribute is the luminance of the colour, also referred to as value, lightness, or brightness. Luminance is very informative in considering the properties of electrochromic materials, because, with only one value, it provides information about the perceived transparency of a sample over the entire visible range. 
In the present work, a 'virtual colorimeter' was used to calculate chromaticity coordinates from the Fig. 3 visible region absorption spectra. The human eye’s cones' spectral responses are known as l, m and s (long, medium and short) and are linear combinations of the colour matching functions, $\bar{x}, \bar{y}$ and $\bar{z}$, as used for a CIE $19312^{\circ}$ Standard Observer. The mathematical relationships between the CIE tristimulus values $X, Y$ and $Z$ and the colour matching functions are given by equations (1-3), where $I(\lambda)$ is the normalised spectral power distribution at a given wavelength.

$$
\begin{aligned}
& X=\int_{300}^{780} I(\lambda) \bar{x}(\lambda) \mathrm{d} \lambda \\
& Y=\int_{300}^{780} I(\lambda) \bar{y}(\lambda) \mathrm{d} \lambda \\
& Z=\int_{300}^{780} I(\lambda) \bar{Z}(\lambda) \mathrm{d} \lambda
\end{aligned}
$$

The CIE recommends that the integration can be carried out by discrete numerical summation, and such computation is straightforward when using a computer spreadsheet:

$$
\begin{aligned}
& X=\sum_{\lambda} I(\lambda) \bar{x}(\lambda) \Delta \lambda \\
& Y=\sum_{\lambda} I(\lambda) \bar{y}(\lambda) \Delta \lambda \\
& Z=\sum_{\lambda} I(\lambda) \bar{z}(\lambda) \Delta \lambda
\end{aligned}
$$

The normalised spectral power distribution of the sample $I(\lambda)$ is related to the un-normalised spectral power distribution of the sample $\varnothing(\lambda)$ by the equation

$$
I(\lambda)=k \phi(\lambda)
$$

where the normalising constant $k$ is

$$
k=100 / \sum_{\lambda} S(\lambda) \bar{y}(\lambda) \wedge \lambda
$$

The definition of the spectral power distribution $\varnothing(\lambda)$ depends upon whether the analysed light is viewed by reflection or transmission. If viewed by reflection then

$\phi_{\mathrm{R}}(\lambda)=\rho(\lambda) S(\lambda)$

and if viewed by transmission then

$\phi_{\mathrm{T}}(\lambda)=\tau(\lambda) S(\lambda)$

In the above equations, $\rho(\lambda)$ is the ideal spectral reflectance, $\tau(\lambda)$ is the ideal spectral transmittance, and $S(\lambda)$ is the spectral power distribution of the light source, which must be specified. If $S(\lambda)=1$, the light source is also ideal i.e., the light source has the same output at all 
wavelengths. Although chromaticity coordinates can be calculated from reflectance measurements, the spectral data here are all from transmission measurements, therefore, the following equations all involve and refer to transmission (Equation (10)).

From the experimental transmittance measurements, and with knowledge of the spectral power distribution of the light source, the tristimulus values $X, Y$ and $Z$ of the colour are calculated. For colour representation in 2-D space, the tristimulus values are converted to chromaticity coordinates $(x, y, z)$ by equations $(11-13)$

$$
\begin{aligned}
& x=\frac{X}{X+Y+Z} \\
& y=\frac{Y}{X+Y+Z} \\
& z=\frac{Z}{X+Y+Z}=1-x-y
\end{aligned}
$$

The luminance factor $Y_{\mathrm{L}}$ (usually expressed as a \%) is defined as the ratio of the luminance of the transmitter $(Y)$ to that of a perfect transmitter $\left(Y_{0}\right)$ under the same conditions.

$$
Y_{L}=\frac{Y}{Y_{0}}
$$

CIE introduced the CIE $L^{*} a * b *$ (CIELAB) system in 1976, which is a uniform colour space defined to be a geometrical construct containing all possible colour sensations. This CIE $L^{*} a * b^{*}$ space is formulated in such a way that equal distances correspond to colours that are perceptually equidistant, and is a standard commonly used in the paint, plastic, and textile industries. The values of $L^{*}, a^{*}$ and $\mathrm{b}^{*}$ are defined as in equations (15-17)

$$
\begin{aligned}
& L^{*}=116 \times\left(\frac{Y}{Y_{n}}\right)^{1 / 3}-16 \\
& a^{*}=500 \times\left[\left(\frac{X}{X_{n}}\right)^{1 / 3}-\left(\frac{Y}{Y_{n}}\right)^{1 / 3}\right] \\
& b^{*}=200 \times\left[\left(\frac{Y}{Y_{n}}\right)^{1 / 3}-\left(\frac{Z}{Z_{n}}\right)^{1 / 3}\right]
\end{aligned}
$$

where $X_{\mathrm{n}}, Y_{\mathrm{n}}$, and $Z_{\mathrm{n}}$ are the tristimulus values of a perfect reflecting diffuser (as calculated from the background measurement). In the $L^{*} a^{*} b^{*}$ chromaticity diagram, $+a^{*}$ relates to the red direction, $a^{*}$ is the green direction, $+b^{*}$ is the yellow direction, and $-b^{*}$ is the blue direction. The centre of the chromaticity diagram $(0,0)$ is achromatic; as the values of $a^{*}$ and $b^{*}$ increase, the saturation of 
the colour increases.

\subsection{Colour measurement of the ECDs}

Fig. 4 shows the CIE 1931 xy chromaticity coordinates and relative luminance changes for the two viologen concentration ECDs as calculated from the in situ spectra of Fig. 3. The parameters $x$ and $y$ represent the red-to-blue ratio, and the green-to-blue ratio, respectively.

Figure 4 here

We earlier found that the tracks of the CIE 1931 xy coordinates for (colour-reinforcing) Ruthenium purple/methyl viologen ECDs, gave minimal hysteresis on reversibly switching between the 'off' and 'on' states. For the PB/methyl viologen ECDs' (Fig. 4 (a) and (c)), there is significant hysteresis, implying that accurate choice of chromaticity coordinates between the fully 'off' and 'on' states will therefore depend somewhat on the potential direction approached. It is however recognised, that the presence of hysteresis in an ECD may be dependent on the measurement kinetics. In the present work, switching is through potential stepping, as detailed in the caption for Fig. 3. Overlaying the $x y$ data onto the CIE 1931 colour space template, and extrapolation from the white point (in this case coincident with the colourless 'off' state) to the spectral locus, determines the sample hue. The dominant wavelength $\left(\lambda_{\mathrm{d}}\right)$ of the PB/methyl viologen ECD's colour state was $475 \mathrm{~nm}$, as expected, around halfway between that for PB (488 nm) and the methyl viologen radical cation monomer/dimer system (455 nm).

In CIE theory, colours cannot be specifically associated with a given pair of xy coordinates, because the third dimension of colour, lightness, is not included in the diagram. The relative lightness or darkness of a colour is very important in how it is perceived, and is presented as the relative or percentage luminance, $Y_{\mathrm{L}}$, of the sample, to that of the background, $Y_{0}$. Relative luminance values can range from $100 \%$ for white samples (no light absorbed) to zero for samples that absorb all the light. Fig. 4 (b) and (d) show in graphical form the changes in the percentage colorimetric luminance $\left(\% Y_{\mathrm{L}}\right)$ on switching between the 'off' and 'on' ECD states. When the ECD is switched on, the luminance dramatically decreases, as the deep blue colour forms and steadily becomes more saturated.

Fig. 5 shows photographs of the colourless and deep blue states of a PB/10 mM methyl viologen ECD, with the CIE $1931\left(\% Y_{\mathrm{L}}, x\right.$, and $\left.y\right)$ and CIELAB $\left(L^{*} a * b^{*}\right)$ numerical data being given in Table 1 for both a PB/5 mM methyl viologen and a PB/10 mM methyl viologen ECD. 
Figure 5 here

Table 1 here

When the ECDs are in the 'off' state $(-1.00 \mathrm{~V})$, the redox states are the colourless methyl viologen di-cation and the colourless (reduced PB) iron(II) hexacyanoferrate(II). The chromaticity coordinates of the ECDs in the 'off' state $\left(x=0.335, y=0.349\right.$, and $\left.\% Y_{\mathrm{L}}=100\right)$ are close to that of the white point $\left(x=0.332, y=0.348\right.$, and $\% Y_{\mathrm{L}}=100$ ) for a D55 illuminant, demonstrating close to full transparency of the ECD. When the ECD is switched on $(+1.50 \mathrm{~V})$, in an oxidative direction with respect to the PB electrode and a reductive direction with respect the methyl viologen, the ECD changes from near colourless to deep blue due to the formation of the purple methyl viologen radical cation monomer/dimer and the blue iron(II) hexacyanoferrate(II) chromophore. In terms of CIELAB $\left(L^{*} a^{*} b^{*}\right)$ chromaticity coordinates (Table 1 ), with a decrease in $L^{*}$, a very small positive change (towards red) in $a^{*}$ occurs, coupled with a dramatic negative change (towards blue) in $b^{*}$, quantifying the perceived deep blue colour state as a combination of purple and blue. By comparison, the CIELAB $\left(L^{*} a * b^{*}\right)$ chromaticity coordinates of PB as a single film of the same thickness to that used in the ECDs, are $L^{*}=73, a^{*}=-26$ and $b^{*}=-33$. In the ECDs, the presence of the methyl viologen system removes the negative $a^{*}$ chromaticity coordinate in PB, the colour now being a deeper blue, of broad visible region absorption, without a green component.

\section{Conclusion}

The fabrication, in situ spectroelectrochemistry and colour measurement of hybrid ECDs based on a surface-confined metal hexacyanometallate - Prussian blue (PB, containing the iron(III) hexacyanoferrate(II) chromophore) - and solution phase methyl viologen ( $N, N^{\prime}$-dimethyl-4,4'bipyridylium) has been described. On coloration, the iron(II) hexacyanoferrate(II) chromophore is oxidised to the blue (with a green tint) iron(III) hexacyanoferrate(II) chromophore of PB, and the methyl viologen di-cation is reduced to the methyl viologen radical cation monomer/dimer which as a mixture appears purple. The concentration of methyl viologen and its diffusion to the cathode controlled the proportion of surface-confined PB that is switched to the deep blue form and hence the overall absorbance/colour change of the ECD. Using a calculation method based on the integration of experimental spectral power distributions derived from in situ visible region spectra over the CIE 1931 colour-matching functions, the ECD colour stimulus, and the changes that take place on reversibly switching to the colourless form have been calculated. 


\section{Acknowledgement}

We thank Loughborough University and the departmental EPSRC Doctoral Training Grant for provision of a research studentship to TSV.

\section{References}

[1] P.M.S. Monk, R.J. Mortimer, D.R. Rosseinsky, Electrochromism and Electrochromic Devices; Cambridge University Press: Cambridge, UK, 2007.

[2] R.J. Mortimer, Electrochromic materials, Annu. Rev. Mater. Res. 41 (2011) 241-268.

[3] R. Baetens, B.P. Jelle, A. Gustavsen, Properties, requirements and possibilities of smart windows for dynamic daylight and solar energy control in buildings: A state-of-the-art review, Sol. Energy Mater. Sol. Cells 94 (2010) 87-105.

[4] D.R. Rosseinsky, R.J. Mortimer, Electrochromic systems and the prospects for devices, Adv. Mater. 13 (2001) 783-793.

[5] N. R. Lynam, A. Agrawal, Automotive applications of chromogenic materials (pages 46-84) in "Large Area Chromogenics: Materials and Devices for Transmittance Control", edited by C.M. Lampert, C.G. Granqvist, SPIE Optical Engineering Press, Bellingham, Washington, USA (1990). [6] M.B. Robin, The color and electronic configurations of Prussian blue, Inorg. Chem. 1 (1962) 337-342.

[7] P.M.S. Monk, The Viologens: Physicochemical Properties, Synthesis and Applications of the Salts of 4,4'-Bipyridine, J. Wiley \& Sons, Chichester 1998.

[8] E.M. Kosower, J.L. Cotter, Stable free radicals. II. The reduction of 1-methyl-4cyanopyridinium ion to methylviologen cation radical, J. Am. Chem. Soc. 86 (1964) 5524-5527. [9] R.J. Mortimer, J.R. Reynolds, In situ colorimetric and composite coloration efficiency measurements for electrochromic Prussian blue, J. Mater. Chem. 15 (2005) 2226-2233. [10] K-C. Ho, Cycling and at-rest stabilities of a complementary electrochromic device based on tungsten oxide and Prussian blue thin films, Electrochim. Acta 44 (1999) 3227-3235.

[11] J-H. Kang, S-M. Paek, S-J. Hwang, J-H. Choy, Optical iris application of electrochromic thin films, Electrochem. Commun. 10 (2008) 1785-1787.

[12] A. Kraft, M. Rottmann, Properties, performance and current status of the laminated electrochromic glass of Gesimat, Sol. Energy Mater. Sol. Cells 93 (2009) 2088-2092. [13] T-S. Tung, K-C. Ho, Cycling and at-rest stabilities of a complementary electrochromic device containing poly(ethylenedioxythiophene) and Prussian blue, Sol. Energy Mater. Sol. Cells 90 (2006) 521-537. 
[14] K-C. Chen, C-Y. Hsu, C-W. Hu, K-C. Ho, A complementary electrochromic device based on Prussian blue and poly(ProDOT-Et 2 ) with high contrast and high coloration efficency, Sol. Energy Mater. Sol. Cells 95 (2011) 2238-2245.

[15] T-H. Kuo, C-Y. Hsu, K-M. Lee, K-C. Ho, All-solid-state electrochromic device based on poly(butyl viologen), Prussian blue, and succinonitrile, Sol. Energy Mater. Sol. Cells 93 (2009) 1755-1760.

[16] B.C. Thompson, P. Schottland, K. Zong, J.R. Reynolds, In situ colorimetric analysis of electrochromic polymers and devices, Chem. Mater. 12 (2000) 1563-1571.

[17] I. Schwendeman, R. Hickman, G. Sönmez, P. Schottland, K. Zong, D.M. Welsh, J.R.

Reynolds, Enhanced contrast dual polymer electrochromic devices, Chem. Mater. 14 (2002) 31183122.

[18] A. Cirpan, A.A. Argun, C.R.G. Grenier, B.D. Reeves, J.R. Reynolds, Electrochromic devices based on soluble and processable dioxythiophene polymers, J. Mater. Chem. 13 (2003) 2422-2428. [19] B.C. Thompson, P. Schottland, G. Sönmez, J.R. Reynolds, In situ colorimetric analysis of electrochromic polymer films and devices, Synth. Met. 119 (2001) 333-334.

[20] G. Sönmez, I. Schwendeman, P. Schottland, K. Zong, J.R. Reynolds, N-Substituted poly(3,4propylenedioxypyrrole)s: High gap and low redox potential switching electroactive and electrochromic polymers, Macromolecules 36 (2003) 639-647.

[21] B.D. Reeves, C.R.G. Grenier, A.A. Argun, A. Cirpan, T.D. McCarley, J.R. Reynolds, Spray coatable electrochromic dioxythiophene polymers with high coloration efficiencies, Macromolecules 37 (2004) 7559-7569.

[22] G. Sönmez, H. Meng, F. Wudl, Organic polymeric electrochromic devices: Polychromism with very high coloration efficiency, Chem. Mater. 16 (2004) 574-580.

[23] G. Sönmez, C.K.F. Shen, Y. Rubin, F. Wudl, A red, green, and blue (RGB) polymeric electrochromic device (PECD): The dawning of the PECD era, Angew. Chem., Int. Ed. 43 (2004) 1498-1502.

[24] C.A. Thomas, K. Zong, K.A. Abboud, P.J. Steel, J.R. Reynolds, Donor-mediated band gap reduction in a homologous series of conjugated polymers, J. Am. Chem. Soc. 126 (2004) 1644016450.

[25] L. Sacan, A. Cirpan, P. Camurlu, L. Toppare, Conducting polymers of succinic acid bis-(2thiophen-3-yl-ethyl)ester and their electrochromic properties, Synth. Met. 156 (2006) 190-195. [26] S.C. Nunes, V. de Zea Bermudez, M.M. Silva, M.J. Smith, D. Ostrovskii, R.A. Sá Ferreira, L.D. Carlos, J. Rocha, A. Gonçalves, E. Fortunato, Sol-gel-derived potassium-based di-ureasils for 'smart windows', J. Mater. Chem. 17 (2007) 4239-4248. 
[27] E. Unur, J-H. Jung, R.J. Mortimer, J.R. Reynolds, Dual-polymer electrochromic film characterization using bipotentiostatic control, Chem. Mater. 20 (2008) 2328-2334.

[28] P.M. Beaujuge, S. Ellinger, J.R. Reynolds, Spray processable green to highly transmissive electrochromics via chemically polymerizable donor-acceptor heterocyclic pentamers, Adv. Mater. 20 (2008) 2772-2776.

[29] P.M. Beaujuge, S. Ellinger, J.R. Reynolds, The donor-acceptor approach allows a black-totransmissive switching polymeric electrochrome, Nat. Mater. 7 (2008) 795-799.

[30] S. Tarkuc, Y. Arslan Udum, L. Toppare, Tuning of the neutral state color of the $\pi$-conjugated donor-acceptor-donor type polymer from blue to green via changing the donor state of the polymer, Polymer 50 (2009) 3458-3464.

[31] H. Seol, H. Jeong, S. Jeon, Optoelectrochemical properties of copolymer of terthiophene with 3,4-ethlenedioxypyrrole, J. Electroanal. Chem. 636 (2009) 107-112.

[32] R.J. Mortimer, K.R. Graham, C.R.G. Grenier, J.R. Reynolds, Influence of the film thickness and morphology on the colorimetric properties of spray-coated electrochromic disubstituted 3,4propylenedioxythiophene polymers, ACS Appl. Mater. Interfaces 1 (2009) 2269-2276.

[33] S.V. Vasilyeva, E. Unur, R.M. Walczak, E.P. Donoghue, A.G. Rinzler, J.R. Reynolds, Color purity in polymer electrochromic window devices on indium-tin oxide and single-walled carbon nanotube electrodes, ACS Appl. Mater. Interfaces 1 (2009) 2288-2297.

[34] E. Unur, P.M. Beaujuge, S. Ellinger, J-H. Jung, J.R. Reynolds, Black to transmissive switching in a pseudo three-electrode electrochromic device, Chem. Mater. 21 (2009) 5145-5153.

[35] C.M. Amb, P.M. Beaujuge, J.R. Reynolds, Spray-processable blue-to-highly transmissive switching polymer electrochromes via the donor-acceptor approach, Adv. Mater. 22 (2010) 724728.

[36] A.L. Dyer, M.R. Craig, J.E. Babiarz, K. Kiyak, J.R. Reynolds, Orange and red to transmissive electrochromic polymers based on electron-rich dioxythiophenes, Macromolecules 43 (2010) 44604467.

[37] S.V. Vasilyeva, P.M. Beaujuge, S. Wang, J.E. Babiarz, V.W. Ballarotto, J.R. Reynolds, Material strategies for black-to-transmissive window-type polymer electrochromic devices, ACS Appl. Mater. Interfaces 3 (2011) 1022-1032.

[38] C.M. Amb, J.A. Kerszulis, E.J. Thompson, A.L. Dyer, J.R. Reynolds, Propylenedioxythiophene (ProDOT)-phenylene copolymers allow a yellow-to-transmissive electrochrome, Polym. Chem. 2 (2011) 812-814.

[39] A.L. Dyer, E.J. Thompson, J.R. Reynolds, Completing the color palette with spray-processable polymer electrochromics, ACS Appl. Mater. Interfaces 3 (2011) 1787-1795. 
[40] C. Pozo-Gonzalo, M. Salsamendi, A. Viñuales, J.A. Pomposo, H-J. Grande, Highly transparent electrochromic plastic device that changes to purple and blue by increasing the potential, Sol. Energy Mater. Sol. Cells 93 (2009) 2093-2097.

[41] R.J. Mortimer, J.R. Reynolds, An in situ colorimetric measurement study of electrochromism in the di-n-heptyl viologen system, Displays 29 (2008) 424-431.

[42] R.J. Mortimer, T.S. Varley, Quantification of colour stimuli through the calculation of CIE chromaticity coordinates and luminance data for application to in situ colorimetry studies of electrochromic materials, Displays 32 (2011) 35-44.

[43] CIE Technical Report: Colorimetry, third ed., Commission Internationale De l'Eclairage, Vienna, Austria, 2004.

[44] R. J. Mortimer, T. S. Varley, Novel color-reinforcing electrochromic device based on surfaceconfined Ruthenium purple and solution-phase methyl viologen, Chem. Mater. 23 (2011) 40774082.

[45] R.M. Christie, Colour Chemistry; Royal Society of Chemistry: Cambridge, UK, 2001, ch. 2. [46] R.G. Kuehni, Color: An Introduction to Practice and Principles, second ed., John Wiley and Sons, Hoboken, New Jersey, 2005.

[47] G. Wyszecki, W.S. Stiles, Color Science: Concepts and Methods, Quantitative Data and Formulae, second ed., John Wiley and Sons, New York, 1982. 


\section{Figure captions}

Fig. 1. UV-visible region in situ absorbance spectra for the methyl viologen radical cation monomer/dimer system (—) and thin-film Prussian blue (— $(-$ ), each at separate tin-doped indium oxide (ITO)-glass working electrodes. The methyl viologen radical cation monomer/dimer spectrum was recorded at $-0.80 \mathrm{~V}$ during a $100 \mathrm{mV} \mathrm{s}^{-1}$ potential cycle from $0.00 \mathrm{~V} \rightarrow-0.80 \mathrm{~V} \rightarrow$ $0.00 \mathrm{~V}$ vs. Ag/AgCl (3.0 M NaCl) reference electrode, in a $6 \mathrm{mM}$ methyl viologen dichloride/1.0 M $\mathrm{KCl}$ aqueous solution. The thin-film Prussian blue $\left(6.3 \mathrm{mC} \mathrm{cm}^{-2}\right)$ was prepared as for the ECD fabrication and was held at $+0.50 \mathrm{~V}$ vs. $\mathrm{Ag} / \mathrm{AgCl}(3.0 \mathrm{M} \mathrm{NaCl})$ reference electrode in $0.2 \mathrm{M} \mathrm{KCl}$ aqueous solution.

Fig. 2. (a) An optically-transparent ITO/glass electrode $(25 \times 25 \times 1.1 \mathrm{~mm})$, etched with the desired pattern, (b) an etched ITO/glass electrode, electrochemically coated with a thin-film of PB, (c) a separate, etched ITO/glass electrode, with attached spacers, (d) the final ECD whereby the coated electrode has been pre-conditioned and set to its colourless, reduced state prior to its combination with a spacer-ITO/glass electrode, and sealed with epoxy resin.

Fig. 3. UV-visible absorbance responses of ECDs subjected to potential steps from $-1.00 \mathrm{~V}$ (held 0 to $20 \mathrm{~s}$ ) to $+1.50 \mathrm{~V}$ (at $20 \mathrm{~s}$ ) to $-1.0 \mathrm{~V}$ (at $40 \mathrm{~s}$ ). The ECDs consisted of thin-film PB with a layer of aqueous 0.5 M KCl liquid electrolyte containing methyl viologen (at $5 \mathrm{mM}$ ((a), (b), (e)) and 10 $\mathrm{mM}((\mathrm{c}),(\mathrm{d}),(\mathrm{f})))$. The UV-visible absorbance spectra were recorded every $1 \mathrm{~s}$ and for single wavelength measurements ((e) and (f)) every 0.1 s. Plots (a) and (c) are the UV-visible absorbance spectra between 20 and $40 \mathrm{~s}$, and plots (b) and (d) are the UV-visible absorbance spectra between 40 and $60 \mathrm{~s}$. The arrows indicate the direction of change in absorbance. Plots (e) and (f) show the absorbance changes at the $\lambda_{\max }$ in the visible region.

Fig. 4. Calculated colour trajectory in the CIE 1931 color space ((a) and (c)) and relative luminance vs. time ((b) and (d)), for the electrochemical switching of an ECD consisting of PB/methyl viologen (5 ((a) and (b)) and 10 ((c) and (d)) mM). The arrows show the colorimetric path taken during the potential steps $(-1.00 \mathrm{~V}$ to $1.50 \mathrm{~V}$ to $-1.00 \mathrm{~V})$.

Fig. 5. Photographs of a $\mathrm{PB} /$ methyl viologen $\left(10 \mathrm{mmol} \mathrm{dm}^{-3}\right) \mathrm{ECD}$, in (a) its colourless and (b) its coloured state. 
Fig. 1

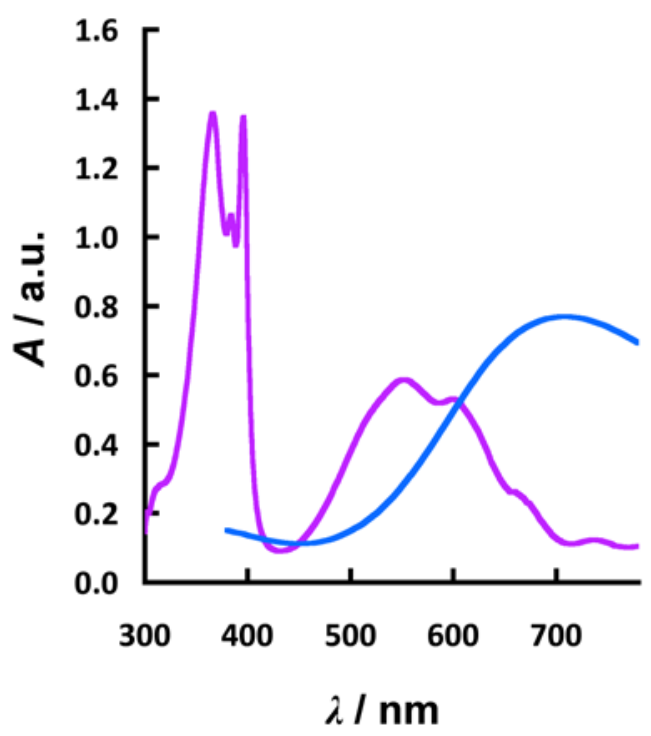




\section{SCHEME 1}

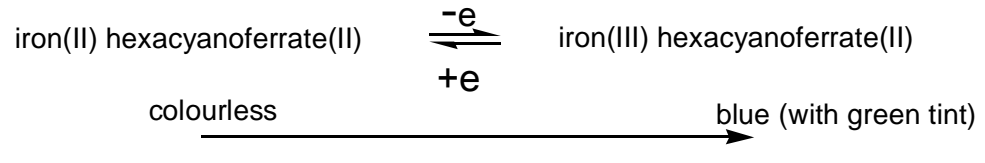

anodically-colouring: colourless to blue (with green tint) on oxidation

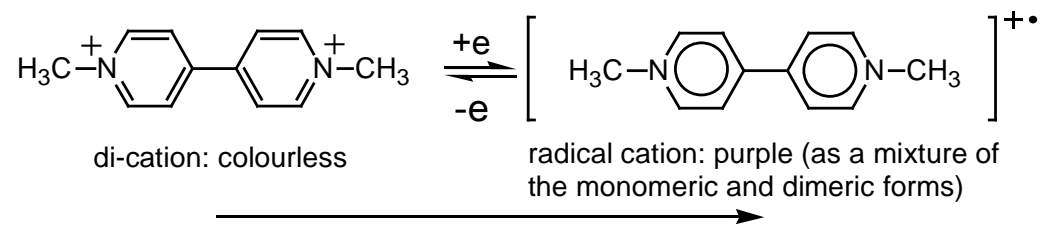

cathodically-colouring: colourless to purple on reduction 
Fig. 2

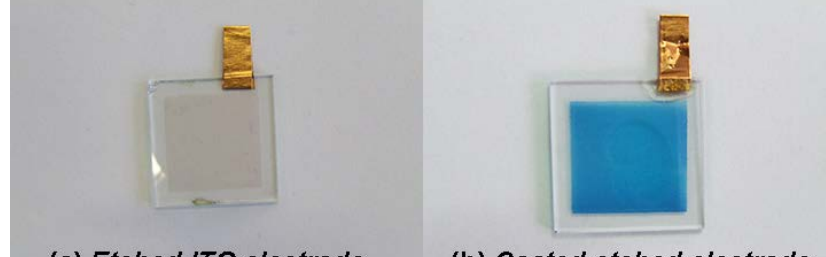

(a) Etched ITO electrode

(b) Coated etched electrode

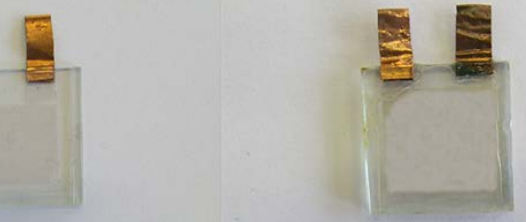

(c) Attached Teflon spacers

(d) Final device

- 19 - 
Fig. 3

(a)

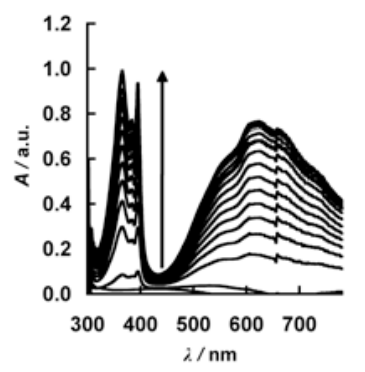

(c)

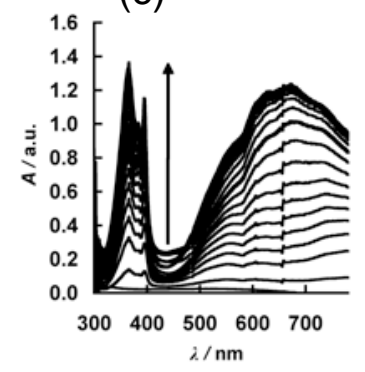

(e)

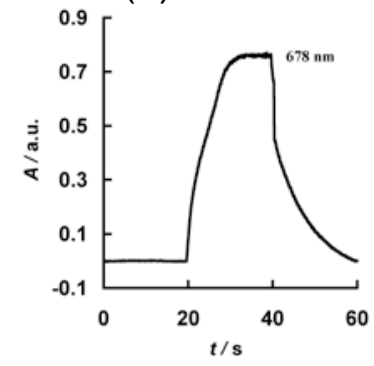

(b)

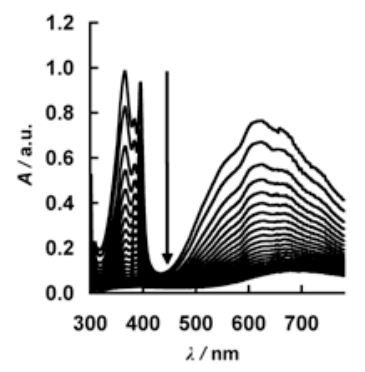

(d)

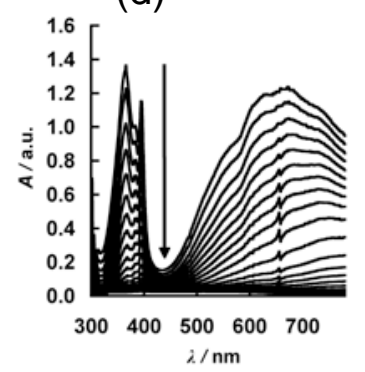

(f)

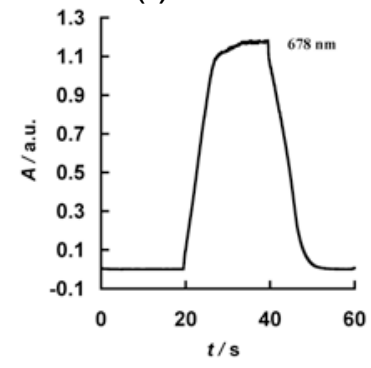


Fig. 4

(a)

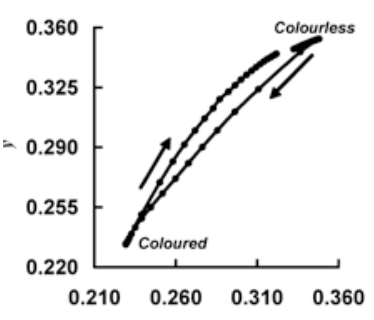

(c)

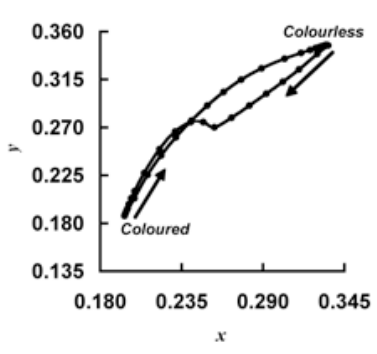

(b)

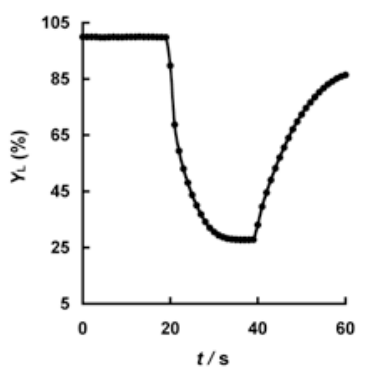

(d)

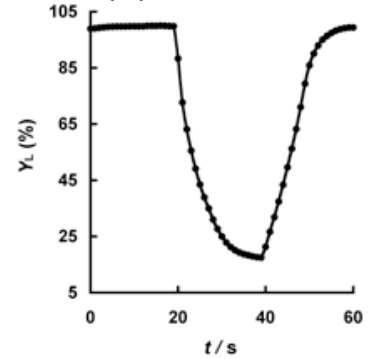


Fig. 5

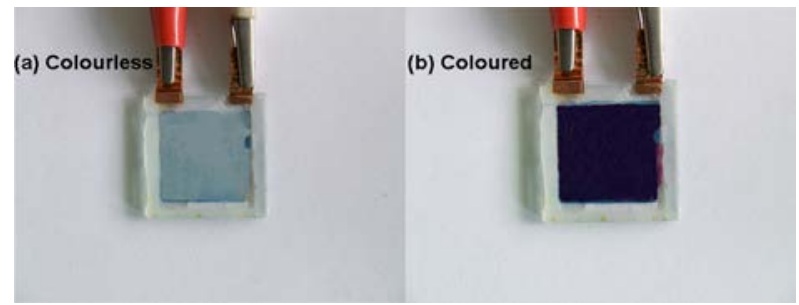


Table 1. Numerical chromaticity coordinates (CIE $1931 \% Y_{L} x y$ and CIELAB) for PB/methyl viologen $\left(5^{\mathrm{a}}\right.$ and $\left.10^{\mathrm{b}} \mathrm{mmol} \mathrm{dm}{ }^{-3}\right)$ ECDs. The ECDs were switched between 'off' and 'on' states via a square wave potential step from $-1.00 \mathrm{~V}$ to $+1.50 \mathrm{~V}$, and vice versa.

\begin{tabular}{l|l|l|l|l|l|l}
\hline ECD state & $x$ & $y$ & $\% Y_{\mathrm{L}}$ & $L^{*}$ & $a^{*}$ & $b^{*}$ \\
\hline 'off' (colourless) & 0.335 & 0.349 & $100 \%$ & 100 & 1 & 1 \\
'on' (coloured) & 0.229 & 0.233 & $27 \%$ & 60 & 3 & -46 \\
'on' (coloured) $^{\mathrm{b}}$ & 0.196 & 0.187 & $18 \%$ & 49 & 9 & -59 \\
\hline
\end{tabular}

